\title{
INTERNACIONAL DE LOS TRABAJADORES E INTERNACIONAL DE LA INTELECTUALIDAD. TAREAS EN EL BICENTENARIO PARA EVITAR LA MASACRE COTIDIANA DE NUESTROS PUEBLOS
}

\author{
Eduardo Devés-Valdés (*)
}

\section{FORMULACIÓN DEL PROBLEMA}

Uno de los motivos de reflexión más importantes, sobre el movimiento de 1907, ha sido la conciencia de pertenencia a la clase trabajadora por sobre las nacionalidades, particularmente entre bolivianos, peruanos y chilenos. Quiero preguntarme sobre este asunto a partir del pensamiento latinoamericano y de los estudios acerca de la trayectoria de nuestra intelectualidad, de nuestra universidad.

Ante esto quiero formular varias preguntas:

Primera pregunta: ¿Cuál es el sentido progresista de una intelectualidad, en el marco de una sociedad y como agente de una sociedad, que no ha sido capaz de construir un mundo desarrollado, un mundo donde la equidad y la justicia prosperen?

Por otra parte, pensar y actuar nacionalmente es uno de los vicios de una intelectualidad encapsulada, y particularmente de una historiografía atada (amarrada, maniatada, enyugada) a lo nacional, una intelectualidad con baja capacidad de pensar más allá de las fronteras y, sobre todo, con muy baja capacidad de actuar más allá de las fronteras.

Segunda pregunta: ¿Cómo constituir a la intelectualidad y a la universidad en agente de un movimiento regional y mundial de reivindicación y de construcción de alternativas mejores? O dicho de otra manera: ¿Cómo aprender de una clase

(*) Investigador del Instituto de Estudios Avanzados (IDEA) de la Universidad de Santiago de Chile.

Correo electrónico: edeves@usach.cl 
trabajadora que logró articularse y crear una conciencia metanacional, más allá de lo nacional, y que fue capaz de articular un proyecto emancipatorio-progresista?

Uno de los tópicos más frecuentes del discurso contemporáneo es el de la sociedad del conocimiento o aquello que entre nosotros se ha llamado la dimensión "aléphica" del conocimiento, es decir la capacidad de éste para ver o para actuar sobre todas las otras dimensiones de la existencia. El conocimiento no como una dimensión más, sino como aquella que permite mejorar la educación, la alimentación, la salud, la justicia, la libertad y, en general, la vida.

Tercera pregunta ¿Cómo pensar la relación entre quienes producen, manejan y difunden el conocimiento y los problemas económicos y sociales y, más radicalmente, con el problema de la masacre de nuestros pueblos?

\section{LOS ORÍGENES DE MI TRABAJO SOBRE LA MASACRE DE 1907}

Hace 20 años (en 1986-1987), cuando escribí Los que van a morir te saludan tenía un leit-motiv fundamental: evitar que se produjera otra masacre como las de 1907 y 1973 sin, por otra parte, retirarse de la historia ni renunciar a las causas progresistas. Pero en ese momento, no intenté formular tareas para la sociedad, pues era tan evidente que la recuperación de la democracia era la tarea clave y aquella que era la puerta para entrar en las demás, que casi esta cuestión salía sobrando. En estos 20 años los avances en diferentes planos han sido manifiestos para Chile y esto nos permite y nos exige pensar un nuevo progresismo. Además, la fecha del bicentenario en 2010 es una coyuntura suficientemente relevante como para reevaluar la historia y lanzar nuevos desafíos. De allí la importancia de ligar la conmemoración de los cien años de la masacre de Iquique con la conmemoración del bicentenario de la independencia. Es decir, asociar 2007 y 2010.

Una de las cosas importantes que se ha afirmado en estos 20 años, en el seno de las redes en las cuales me muevo, es la tarea de pensar regionalmente más que nacionalmente, incluso la tarea de superar el pensamiento nacional para ir más allá de lo nacional, o dicho de otra manera: potenciar un tipo de quehacer intelectual que rompa con las ataduras el paradigma nacional que se ha transformado, me parece, en un obstáculo para entender y para mejorar la situación de nuestra región. En éste y en otros sentidos, he querido formular el desafío del "pensar bien" o del "bienpensar".

Por cierto, no podrían interpretarse las causas de la masacre simplemente como el pensar mal por parte de pampinos y autoridades, pero tampoco podría sostenerse que las equivocaciones, descriterios, prejuicios, dificultades en la concepción de las cosas o en la transmisión de las ideas no tuvieron ninguna importancia. Pero la afirmación de la cuestión del bienpensar que es válida para cualquier ser humano, se hace todavía más importante cuando se está hablando a personas del espacio universitario, es decir, personas que están comprometidas, al menos en principio, con la causa del bienpensar.

Por otra parte, la necesidad de bienpensar se hace tanto más imprescindible 
cuanto más débiles son las personas que se encuentran en determinada situación. Los muy fuertes pueden darse el lujo de pensar mal, porque su poder puede salvarles. Si la piedra se equivoca y da al cántaro es éste el que se quiebra, si es el cántaro el que se equivoca y da a la piedra también el que se quiebra es el cántaro. Si el cántaro decide dar a la piedra con tanta fuerza como para quebrarla, puede que tenga éxito y lo logre, pero a costa de partirse en mil pedazos y por tanto su mismo éxito será, a la postre, su peor fracaso. Para los débiles un pensamiento en falso puede significarles la muerte. Eso ocurrió con los pampinos y eso ocurrió en 1973. Entender la relación entre ambos acontecimientos fue la tarea que me propuse en 1987 cuando escribí el libro, es decir entender si habían existido similares defectos en el pensar, en las maneras de concebir las cosas, en ambas ocasiones. Hoy, acercándonos al 2010 quiero agregar la cuestión acerca de lo que ha ocurrido con una América Latina débil, que sistemáticamente se da contra las piedras y que no alcanza los éxitos necesarios para el bienestar de sus pueblos.

\section{LA MASACRE DE IQUIQUE Y LA EVALUACIÓN DEL CENTENARIO}

La masacre de Iquique opacó el centenario. Fue la masacre más grande que recordaba la memoria nacional, aunque en la guerra civil del 1891 o en las represiones o guerras con los pueblos indígenas había muerto mayor cantidad de gente. Por cierto, las masacres de 1973, y las de años siguientes, son notoriamente mayores, más frías y premeditadas.

Pero a la hora de pensar el bicentenario, y los pocos éxitos de América Latina cabe preguntarse si no hay un estilo de "pensar-mal" que marca las masacres y las incapacidades para gestionar a nuestros países. ¿Podría hablarse de una "cultura del mal-pensar" y correlativamente del "mal-actuar"?

En América Latina, Chile es el país que terminó mejor el siglo XX y que ha empezado mejor el siglo XXI. El éxito relativo en el aumento de democracia y en la disminución de la pobreza, tanto como el fracaso de países cercanos en cuestiones económicas y políticas, ha hecho que nuestra población crea o sienta, como también lo creen o sienten en otros países de la región, que Chile en comparación, relativamente, se encuentra mejor. Probablemente uno de los mayores indicadores para medir esto es que desde Chile la gente no se va o se va poco en tanto que de otros países se va mucha o querría irse, y que alguna de esa gente decide venirse a vivir a Chile. Pero este bienestar de Chile es ambiguo, pues conlleva la idea que si estamos relativamente bien, podríamos estar mucho mejor, y ello en varios sentidos.

Me interesa hablar, en este caso, principalmente para el medio universitario y del profesorado y preguntarme (preguntarle, preguntarnos) por las maneras en que este medio (nuestro medio) podría (debería) enfrentar la tarea de construir sociedades mejores, en el sentido de hacer más felices y poderosos a sus pueblos. Existe entre las personas que viven en América Latina y el Caribe (ALC) el sentimiento que viven mal: los permanentes y crecientes indicadores de personas que buscan maneras de emigrar es una forma de mostrar que se cree que en otros lugares la gente vive mejor 
y que no puede esperarse más tiempo; correlativamente existe un sentimiento de debilidad, inseguridad o precariedad y es muy nítida igualmente la convicción que sufrimos a manos de poderes mucho mayores que los nuestros: poderes imperiales, neo-coloniales, de empresas multinacionales, etc. ¿Cómo asumir estos desafíos desde el medio universitario y desde la intelectualidad?

Dos posiciones cortoplacistas, a mi juicio, equivocan la manera de buscar una solución. La primera: renunciemos al quehacer universitario y transformémonos en personas que viven en el seno del pueblo, para desde allí cambiar la situación; la segunda: no abandonemos el quehacer universitario pero abandonemos el estudio para transformarnos en agitadores dentro de este espacio, para lograr que solidarice con las causas de los pobres o marginados del sistema. Entre ambos casos, lo común es asumir que la actividad del conocimiento es irrelevante para hacer nuestros pueblos más felices y/o poderosos.

Pero, por otra parte, existe una vieja convicción que saber es poder y otra más actual que dice que en la era del conocimiento y la información, cada vez más, quienes manejan esos elementos pueden mejorar más fácilmente su realidad. Simultáneamente se dice que los pueblos más poderosos en la actualidad son los que producen más conocimiento.

¿A qué se debe entonces la convicción tan frecuente en ALC que para mejorar la condición de nuestros pueblos hay que hacer actividades extra-universitarias o ajenas al conocimiento? ¿A qué se debe entonces que se ubique la ética fuera de la actividad del conocimiento, imaginando al conocimiento como una especie de pérdida de tiempo para quienes desean contribuir a la felicidad y al poder de nuestras sociedades? ¿A qué se debe que haya frecuentes manifestaciones a favor de causas sociales o ecológicas y no a favor del aumento y mejoramiento del conocimiento? ¿Por qué no hay o se dan tan escasos movimientos estudiantiles o de profesores que pidan mejoramiento de las bibliotecas, aumento de docentes con doctorado, concursos transparentes, aumento en las exigencias curriculares, obligatoriedad de la investigación, transformación del conocimiento en tecnologías útiles para la sociedad?

A mi juicio se debe a un razonamiento que se encuentra en un círculo vicioso del que todos somos víctimas: Como ALC no produce conocimiento importante, como no hemos hecho aportes al mundo en inventos, patentes, teorías, tecnologías, medicamentos, descubrimientos, etc., entonces deducimos que en el futuro tampoco lo vamos a lograr y que la actividad universitaria es casi un lujo egoísta para quienes desean ganar dinero o poder para sí mismos, pero que ello aportará poco y nada a nuestras sociedades. Esta convicción de que ALC ha aportado poco y nada al saber mundial se confirma en nuestra vida cotidiana: ni el automóvil, ni el computador, ni los electrodomésticos, ni los medicamentos, ni las teorías sociológicas, pedagógicas o biológicas que utilizamos han sido desarrollados por gente de ALC. Esto vuelve a confirmarse cuando nos damos cuenta que nuestros Estados no tienen confianza en la comunidad universitaria y científica y que le asignan harto bajo presupuesto en relación a lo que ocurre en lugares que van a la vanguardia del poder mundial. Ello se confirma una vez más cuando vemos los medios de comunicación y nos damos 
Internacional de los trabajadores e internacional de la intelectualidad.

Tareas en el bicentenario para evitar la masacre cotidiana de nuestros pueblos

cuenta que la universidad aparece cuando hay huelgas o desmanes, pero nunca cuando se ganó un premio Nobel o se hizo un gran descubrimiento, porque ello jamás ocurre. Y lo confirmamos nuevamente cuando advertimos que la industria invierte poco y nada en investigación, pues tampoco ésta cree que la comunidad científico-tecnológica del país le va a solucionar ningún problema ni le va a generar mejores resultados.

\section{LA MASACRE COTIDIANA}

No me parece que deba actualmente considerarse como escenario posible en ALC ni guerras internacionales ni grandes masacres a nivel nacional. No creo que hayamos llegado a un estado de paz perpetua, pero no me parece que catástrofes de ese tipo deban considerarse en un escenario inmediato. Mucho más significativa me parece la masacre de nuestros pueblos por la miseria, la pobreza, la insalubridad, etc. Esta masacre se sigue cometiendo cotidianamente en ALC con el $40 \%$ a $45 \%$ de nuestra población. Los indicadores de desarrollo humano son relativamente bajos y progresan muy lentamente.

En lo que respecta al poder mundial, la región américo-ibera empeora su situación relativa respecto de las economías más dinámicas del mundo. De hecho, dice el Banco Mundial, la composición del PIB está estrechamente relacionada con el bajo nivel de productividad y la falta de incorporación de conocimiento y progreso técnico al proceso productivo. A la par que en la mayoría de los países de la región américoibera se ha incrementado la productividad laboral en los últimos 15 años, la distancia con respecto a las economías más dinámicas del resto del mundo se ha acentuado, salvo en el caso de Chile de manera manifiesta y algo en República Dominicana. Es decir, si bien la productividad del trabajo en nuestra región ha aumentado en términos absolutos, si la comparamos con el crecimiento que han tenido en las economías más dinámicas, en realidad ha decaído. La productividad laboral se encuentra estrechamente asociada a los niveles de calificación de la mano de obra.

A otras economías les ha ido notoriamente mejor. Hace unos 50 años Corea del Sur estaba en una situación parecida a la de Bolivia. Hoy día su ingreso per cápita es unas 15 veces superior al de Bolivia, produce 10 veces más doctores per cápita que ALC y más de 50 veces más doctores que algunos países de ALC y 800 veces más patentes per cápita que ALC y obviamente tiene menos de un $10 \%$ de pobres, en tanto que ALC tiene más del $40 \%$. Pocas cosas como ésta revelan tanto la incapacidad de ALC para pensar bien. ALC como conjunto, todas las clases, todas las profesiones, gremios y ocupaciones, y en particular el medio intelectual (de universitarios, profesores, investigadores, profesionales) es responsable de la masacre cotidiana de sus pueblos.

La primera tarea progresista es mejorar los niveles de desarrollo humano de nuestros pueblos, cosa que pasa en gran parte, no únicamente, por mejorar los niveles educacionales en un amplio sentido. Para mejorar la productividad del trabajo, para mejorar el tratamiento y la formación de los hijos, para mejorar la alimentación de 
las familias, para aumentar la capacidad de diálogo y tolerancia, para aumentar las exigencias de respeto, para presionar a nuestros representantes políticos tanto como a empresas y reparticiones públicas a perfeccionar sus servicios, para exigir una mejoría en los medios de comunicación que facilite disminuir la estupidez, y así muchas cosas más es necesaria una educación de mayor calidad y más abundante y ello pasa por una universidad que desempeñe mejor su tarea. Porque la educación es aléphica, es decir, permite verse a sí misma y ver todas las otras dimensiones de la realidad. Pero, no debe pensarse que ésta sea la solución independiente ni automática a todos los problemas de la humanidad.

\section{VUELTA AL INTERNACIONALISMO, AHORA COMO INTEGRACIONISMO Y COLABORACIÓN EN FAVOR DEL CONOCIMIENTO}

Se ha dicho que uno de los elementos más destacados de la huelga de 1907 fue la solidaridad de los trabajadores por sobre las nacionalidades. Por otra parte, a comienzos del siglo XX, se planteó el proyecto integracionista latinoamericano asociado a una defensa de la región respecto del creciente poderío de los Estado Unidos. Esta manera de pensar la unidad de ALC inspiró una tendencia a lo largo de todo el siglo. ¿Tiene sentido éste $u$ otro integracionismo, asociado a las redes de intelectuales y universitarios? ¿Podemos imaginar alguna suerte de solidaridad de las comunidades intelectuales más allá de nuestras nacionalidades latinoamericanas? ¿Es posible imaginar alguna suerte de sinergia debida a esta solidaridad? ¿Es imaginable pensar que los pueblos latinoamericanos vivirán mejor con la cooperación?

Felipe Herrera, uno de los mayores pensadores y agentes integracionistas en el continente durante el siglo XX y presidente del Banco Interamericano de Desarrollo (BID), prometió que éste sería el banco de la integración y el banco de la universidad latinoamericana. El BID contribuyó a financiar importantes proyectos de desarrollo, que articularon a diversos países, como por ejemplo la represa de Itaipú, a la vez que financió proyectos en numerosas universidades. Ahora bien, lo que no logró fue transformar a la universidad latinoamericana en una institución integrada y sinergizada. Los aportes de Herrera o del BID no se transformaron, de manera importante, en iniciativas intelectuales o científico-tecnológicas.

Algo parecido puede decirse de numerosos agentes estatales que pueden financiar instituciones académicas, firmar acuerdos de complementación, crear incluso organismos pero si no existe una comunidad académica que haya creado relaciones y confianzas con gentes de otros países no se producirán equipos integrados de trabajo intelectual. Esta iniciativa corresponde en primer lugar a las redes intelectuales.

La pequeñez de nuestras comunidades intelectuales las bloquea en un provincianismo inhibitorio. La colaboración es clave para obligarlas a superarse a sí mismas, tanto por la mayor recepción de información como por la competencia a que son sometidas. La colaboración mejora la calidad de la producción. 
Si de lo que se trata es de impulsar la investigación y el conocimiento y a partir de allí posibilitar el desarrollo de las fuerzas productivas intelectuales, ha de asumirse que son los propios agentes intelectuales los llamados a incentivar este proceso. Sin embargo, ello no debe suponer que los impulsos provenientes del Estado, de la industria, de la política, o de la seguridad deban ser inhibidos o despreciados. Más aún, la legitimidad de la investigación y del financiamiento que el mundo intelectual espera, sólo podrá alcanzarse en la medida que la investigación pruebe su aporte a la sociedad y a la economía.

En otras palabras, si la colaboración intelectual entre los países de ALC debe producir sinergia, el crecimiento de la actividad intelectual debe producir sinergia social y económica, y si ello no ocurre diré que no se justifica la demanda por mayores financiamientos para investigación y universidad. Aquí se topa el asunto del pacto científico-tecnológico, unos prometen y otros exigen: la intelectualidad promete un conocimiento válido y exige financiamiento; la sociedad promete financiamiento y exige un conocimiento válido.

\section{LA TAREA DE EVITAR LA MASACRE COTIDIANA EN EL BICENTENARIO}

Mi invitación a ustedes es a evitar la masacre cotidiana de nuestros pueblos y para ello asumir las siguientes convicciones-tareas:

- Que el conocimiento es clave para mejorar las más diversas dimensiones de la vida.

- Que la necesidad del conocimiento y del "bienpensar" es particularmente importante para sociedades débiles como las latinoamericanas, ya que su debilidad se debe, en parte, a su incapacidad de apreciar y generar el conocimiento.

- Que para mejorar los niveles de conocimiento debemos mejorar los niveles de calidad y de honestidad intelectual y social, en nuestras instituciones educacionales y en toda nuestra cultura.

- Que si queremos mejorar la producción de conocimiento y los niveles de calidad y honestidad, debemos servirnos de procesos de colaboración intelectual y universitaria con nuestros vecinos de ALC y, por cierto, con todo el mundo.

- Que la intelectualidad y más ampliamente el espacio de universitarios, docentes, etc., debe asumir una posición activa para ejercer su capacidad y no renunciar a su trabajo específico, por una parte haciendo los debidos aportes y por otra convenciendo a la sociedad de esta posibilidad.

- Que podemos generar, a nivel de la sociedad civil intelectual y universitaria, un movimiento de reforma intelectual y moral que disminuya o evite la masacre cotidiana de nuestros pueblos y que ésta es la tarea más importante a la hora de conmemorar los cien años de la masacre de Iquique y es una propuesta decisiva para el Bicentenario de Chile y de América Latina. 